Journal of Advanced Research in Materials Science

Journal homepage: www.akademiabaru.com/arms.html ISSN: 2289-7992

\title{
Characteristics of Continuous Unidirectional Silk Fibre Reinforced Epoxy Composites
}

\author{
Zuraidah Zainudin¹, Noor Izyan Syazana Mohd Yusoff ${ }^{1}$, Mat Uzir Wahit ${ }^{1,2,{ }^{*}}$ \\ Department of Polymer Engineering, Universiti Teknologi Malaysia, Johor, 81310, Malaysia \\ Centre for Advanced Composite Materials, Universiti Teknologi Malaysia, Johor, 81310, Malaysia
}

\section{ABSTRACT}

Bombyx mori silk fibre has some prominent features such as high ductility and strength due to its high crystallinity in molecular structure. This research aims to characterise and evaluate the mechanical and water absorption properties of continuous unidirectional silk fibre reinforced epoxy composites with various fibre loading ( 0 to $30 \mathrm{wt}$.\%). The silk fibre was obtained through degumming treatment of silk cocoon using $1 \mathrm{wt} . \%$ of sodium bicarbonate solution. The composites materials were prepared using the hand lay-up method. The silk fibre reinforced epoxy composites with $30 \mathrm{wt} . \%$ of fibre loading acquired the highest value of tensile, flexural, and impact properties. The impact fracture of the composites was analysed using scanning electron microscopy (SEM). The SEM micrographs of composites reveal that the presence of pull-out fibres and matrix cracking was less with increasing fibre loading, indicating the improvement of interfacial bonding between fibre and matrix. The water absorption study shows that water absorption properties increased with increasing fibre loading.

Keywords:

Silk; Epoxy; Composites; Fibre, Mechanical Properties; Water Absorption

Copyright $@ 2020$ PENERBIT AKADEMIA BARU - All rights reserved

\section{Introduction}

Many literatures including books, research papers, and articles have been focusing on utilising synthetic fibre such as glass, carbon, and Kevlar as a reinforcement in composite materials. The common polymer matrix utilised in the composite industry is epoxy resin due to many advantageous offered such as excellent resistance to moisture, solvents and chemical attacks, good thermal resistance, low shrinkage, excellent adhesion, and excellent mechanical strength [1-2]. However, epoxy is known to possesses brittleness and low fracture toughness properties, which limit its performance in the composites industry [3-4]. The toughness of epoxy can be improved either by blending with rubber or incorporating with fiber. However, by adding synthetic fibre in polymer matrix can contribute to several issues such as high cost, abrasive to machine, risky to human health, non-biodegradable, and not environmental friendly [5-8]. Therefore, researchers create alternatives by employing natural fibre as a reinforcing agent in the polymer matrix. Natural fibre such as kenaf,

\footnotetext{
* Corresponding author.

E-mail address: mat.uzir@cheme.utm.my (Mat Uzir Wahit)
}

https://doi.org/10.37934/arms.69.1.1628 
jute, hemp, and sugar palm is a suitable replacement for synthetic fibre due to its excellent properties such as biodegradable, high availability of resources, environmental compatibility, good thermal properties, high mechanical properties, and non-abrasive to machine [8-11].

Bombyx mori silk fibre is a prominent natural fibre that exhibits excellent mechanical properties that are comparable to those of other plant fibres [12]. The B. mori fibres are abundant in Asia countries such as Thailand, Vietnam, Japan, and Malaysia. It has been utilized in many applications such as currency exchange, hunting equipment (fishing poles, crosshair, bowstrings or fishing nets), paper sheets, textile goods, and biomedical application (wound stitching and biomedical scaffolds) [13-15]. The two major proteins that available in B. mori fibres are: (1) fibroin (70\%-75\%), which is mainly made by the hydrophobic and non-polar glycine and (2) minor compounds such as alanine, serine and other amino acids, and sericin (20\%-15\%), which consist of highly hydrophilic and polar side groups such as serine and aspartic acids [16]. The compact structure of amino acid chains forming a high number of hydrogen bonds between them, resulting in higher mechanical strength and thermal properties of silk fibre [17-22].

Several attempts have been made to reinforce the silk fibre in thermoplastic and thermoset polymers to improve the mechanical properties in polymer matrix such as gelatin, polylactic acid (PLA), poly( $\varepsilon$-caprolactone), and others [11, 23-25]. Li et al., [24] reported that the tensile and flexural strengths of silk fibre reinforced poly( $\varepsilon$-caprolactone) composite linearly increased up to 35 and 45 wt.\% of fibre loading. Ho et al., [26] also reported that the Young's and flexural moduli of short silk fibre reinforced PLA composite increased by $27 \%$ and $2 \%$, respectively. Shubra et al., [25] incorporated silk fibre to gelatin polymer material using compression moulding, which enhanced the tensile modulus by $400 \%$, tensile strength by $258.9 \%$, bending modulus by $452.9 \%$, bending strength by $317.2 \%$, and impact strength by $264.3 \%$. Limited studies on the silk fibre reinforced epoxy composites have been reported. Shah et al., [27] illustrated that silk fibre possesses unique properties which leads to the potential as the new reinforcement/fillers for epoxy composites due to its high specific strength. However, the mechanical properties of composite reinforced with silk fibre such as tensile, flexural, and impact properties have not been mentioned. On the other hands, Yang et al., [28] proved that the impact properties of epoxy composites were greatly enhanced as the volume fraction of silk fibre in the composites was increased.

Based on the literature studies, silk fibres have good potential to be used as a reinforcement in polymer composites, whether in thermoplastic or thermoset matrix. However, the incorporation of unidirectional silk in epoxy composites has not been reported. Therefore, this research aims to explore the effect of unidirectional silk fibre loading ( 0 to $30 \mathrm{wt} . \%$ ) on the mechanical properties of the composites such as tensile, flexural and impact properties.

\section{Methodology}

\subsection{Materials}

The liquid epoxy resin grade DER 331 (a liquid reaction product of epichlorohydrin and bisphenol A) and cycloaliphatic amine hardener (JOINTMINE 905-3s) were supplied by Innovative Pultru- sion Sdn Bhd (Negeri Sembilan, Malaysia). B. mori silk cocoon was purchased from The Queen Sirikit Sericulture Centre Surin, Thailand as shown in Figure 1. Both sodium bicarbonate and acetone were obtained from Sigma Aldrich. 


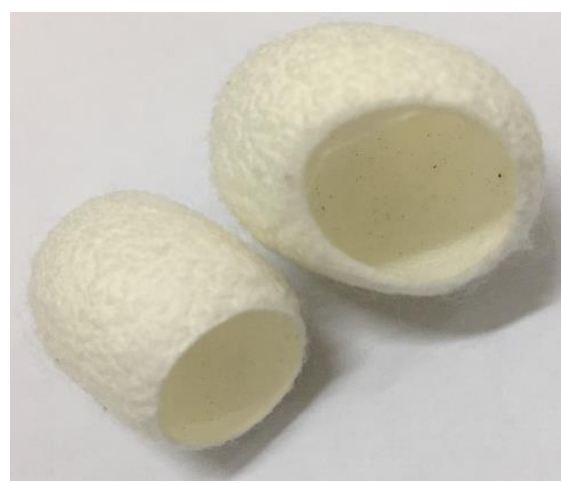

Fig. 1. Bombyx Silk cocoon

\subsection{Silk Degumming}

Figure 2 shows the degumming process. Silk cocoons were immersed in sodium bicarbonate solution $(0.1 \% \mathrm{w} / \mathrm{w})$ for $1 \mathrm{hr}$ at $100{ }^{\circ} \mathrm{C}$ to remove sericin and obtain the fibre. Then, the fibres were washed with distilled water containing a few drops of acetic acid. The fibres were washed with distilled water until all $\mathrm{Na}_{2} \mathrm{CO}_{3}$ was removed, which indicates that alkalinity is no longer detected. After washing, the fibres were air dried for $72 \mathrm{hr}$.

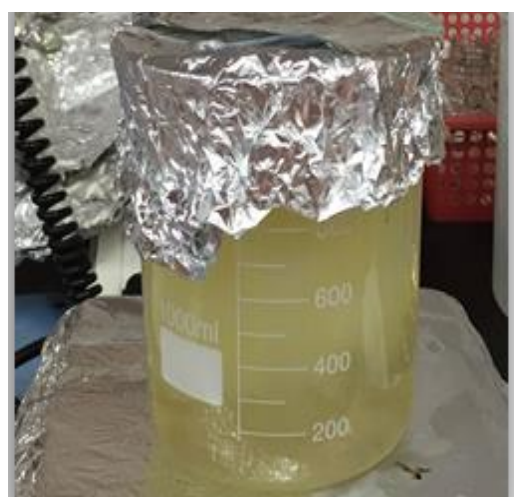

(a) Silk in degumming solution containing $0.1 \mathrm{w} / \mathrm{w} \mathrm{Na} 2 \mathrm{CO} 3$

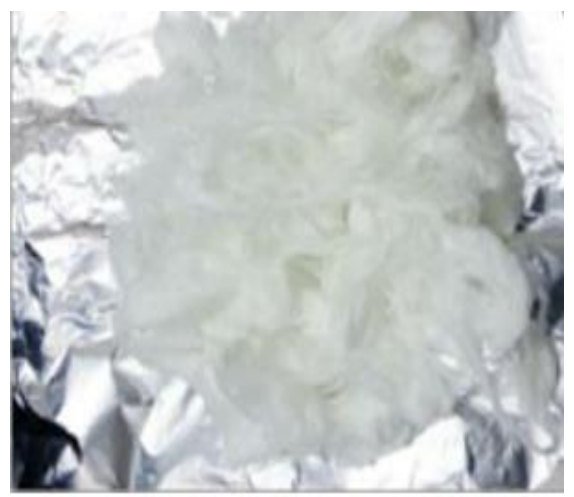

(b) Degummed silk fibres before drying

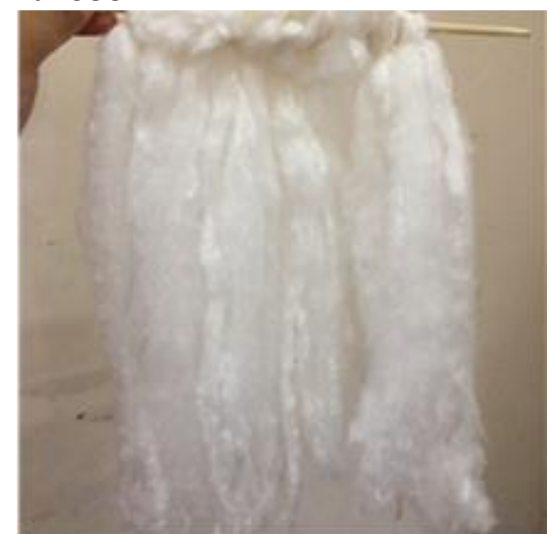

(c) Degummed silk fibres after drying Fig. 2. Silk Degumming Process

\subsection{Fabrication of Composites}

The silk fibres were arranged uni-directionally to the average length of $30 \mathrm{~cm}$ and spread according to the mould size. The epoxy resin and hardener were mixed in a 2:1 ratio. The composite 
specimens for treated fibres were made by the hand lay-up technique in the mould using the fibre weight percentage from $0 \%$ to $30 \%$ as shown in Figure 3. Finally, the specimens were cured at room temperature for approximately $24 \mathrm{hr}$ under clamped condition and the sample was obtained as shown in Figure 3.

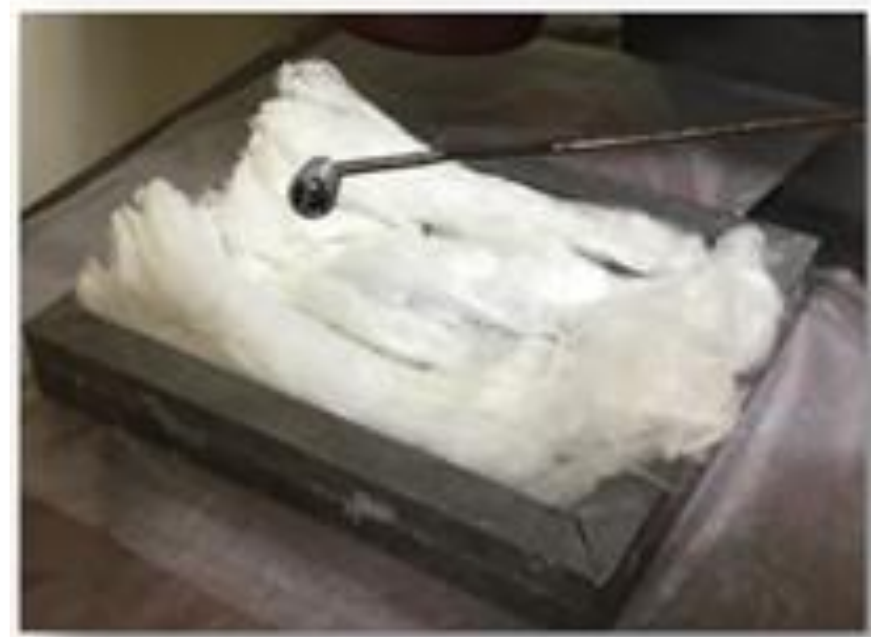

(a) Silk fibre is arranged unidirectionally

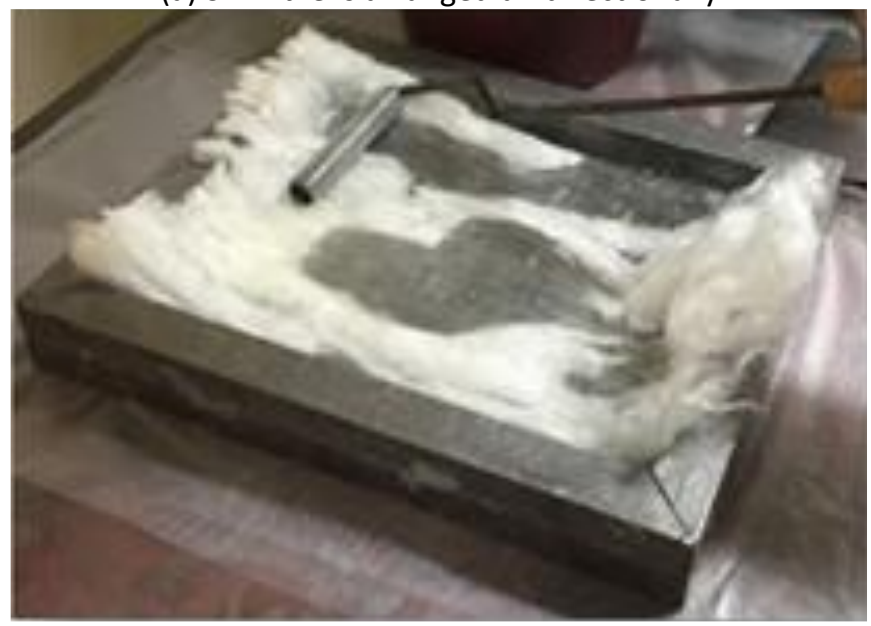

(c) Epoxy is poured into top of arranged fibre

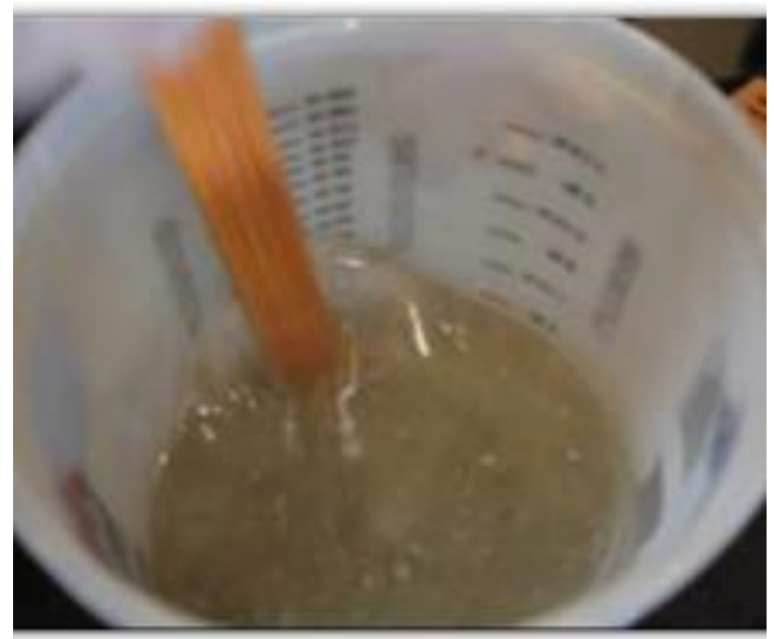

(b) Epoxy and hardener mized together in ratio (2:1)

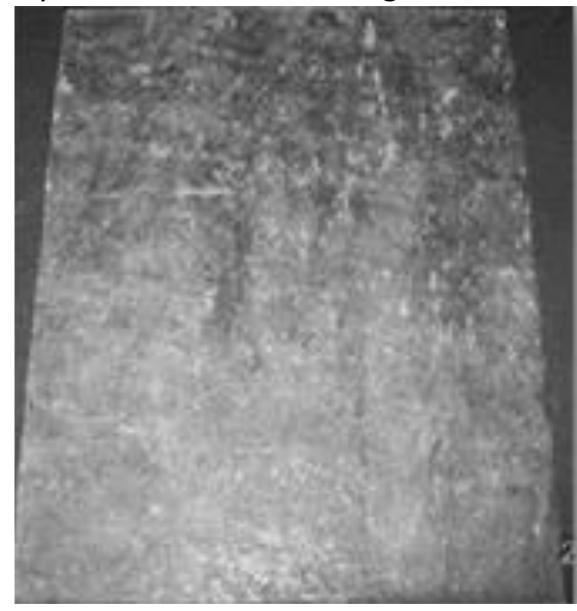

(d) Composite is obtained after curing

Fig. 3. Fabrication of silk fibre reinforced epoxy composite using hand lay-up technique

\subsection{Mechanical Test}

The setup of tensile test and flexural test were shown in Figures 4 and 5 . The specimens of pure epoxy and composites were tested for tensile strength according to the ASTM D638 standard using the Instron Universal Testing Machine Model 5582. The size of the tensile testing samples used was $115 \times 19 \times 4 \mathrm{~mm}$. The crosshead speed was set to $3 \mathrm{~mm} / \mathrm{min}$. The pure epoxy and composites were tested for flexural strength under a three-point bending using the Instron Universal Testing Machine Model 5582 according to the ASTM D790 standard. The size of the flexural testing samples used was $120 \times 20 \times 4 \mathrm{~mm}$. The machine was operated at a crosshead speed of $3 \mathrm{~mm} / \mathrm{min}$ and a span of 60 $\mathrm{mm}$. The Izod impact test was carried out on the notched impact specimens according to the ASTM D 256 standard using Izod impact tester LS-22005. The size of the impact testing sample used was 65 $\times 10 \times 3.5 \mathrm{~mm}$. 


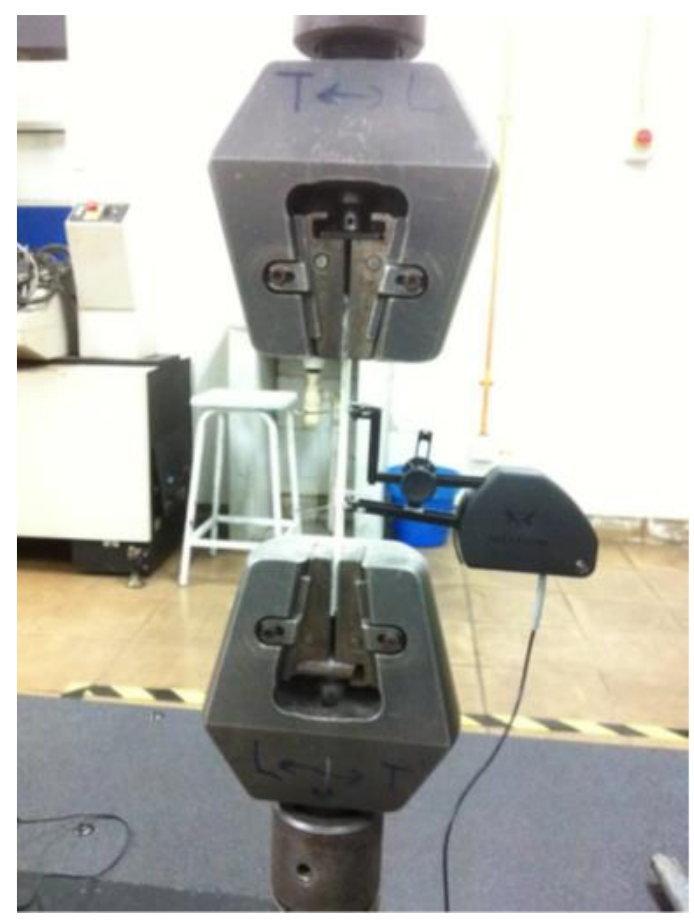

Fig. 4. Tensile specimen placed on Universal Testing Machine

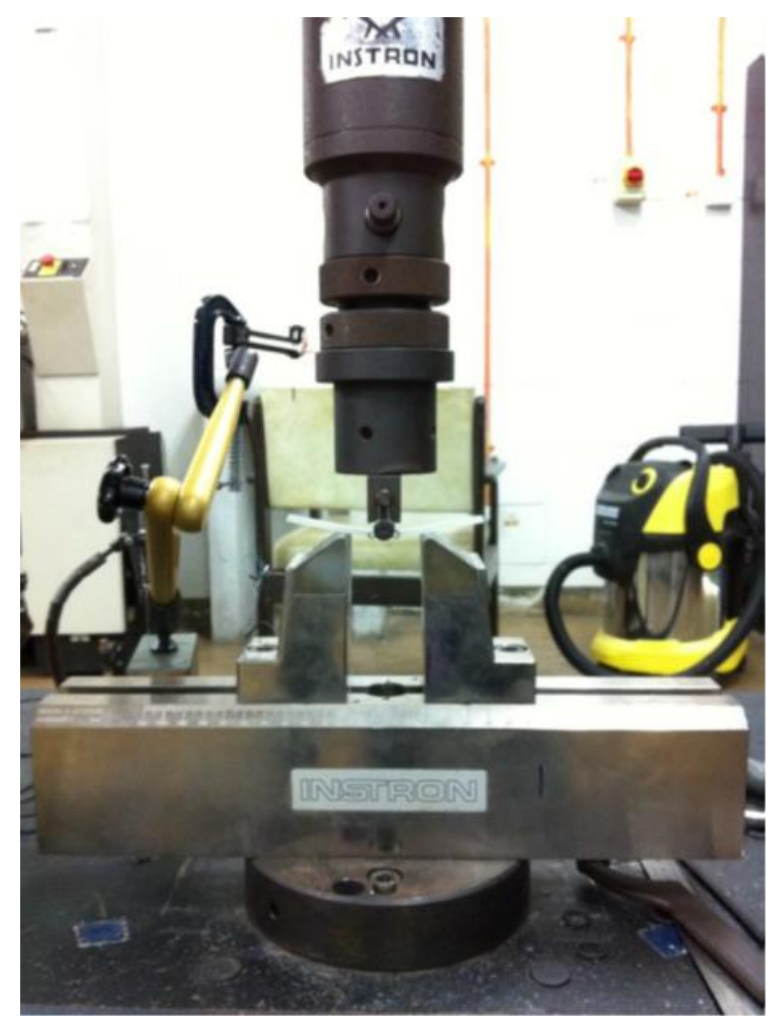

Fig. 5. Flexural specimen during bending process

\subsection{Scanning Electron Micrography (SEM)}

The fracture samples from the impact test were used to determine its morphology of the composites. The parameter for each sample was set to $1200 \times$ magnification to obtain a clear image by using the Philip XL40 Scanning Electron Microscopy. To avoid the effect of electrostatic charge and poor 
image resolution, all the surfaces of the sample were examined after they were sputter coated with gold.

\subsection{Water Absorption Test}

The samples were cut into strips of $72.6 \times 25.4 \times 4 \mathrm{~mm}$ according to the ASTM D570 standard. First, the samples were dried in an oven for $24 \mathrm{hr}$ at $60 \circ \mathrm{C}$. The samples were weighed immediately, $W_{i}$. Later, the samples were fully immersed in distilled water at room temperature. The sample was weighed for every 2 days until the weight of the sample become constant, $W_{f}$. The percentages of water absorption were determined using Eq. (1).

Water Absorption $(\%)=\frac{\text { Initial weight }\left(\mathrm{W}_{i}\right)-\text { Final weight }\left(\mathrm{W}_{\mathrm{f}}\right)}{\text { Initial weight }\left(\mathrm{W}_{i}\right)}$

\section{Results and Findings}

\subsection{Mechanical Properties}

Figure 6 shows the typical engineering stress-strain curves of the silk fibre reinforced epoxy composites and pure epoxy. The tensile stress was obtained by observing the highest tensile strength as shown in Figure 6, while the Young modulus was obtained by the initial slope or the gradient of the stress vs strain graph. The elongation at break was obtained where the samples displayed the brittle failure. The results show that when the fibre loading increased, the tensile strength and tensile modulus of the composites increased to $30 \mathrm{wt} . \%$.

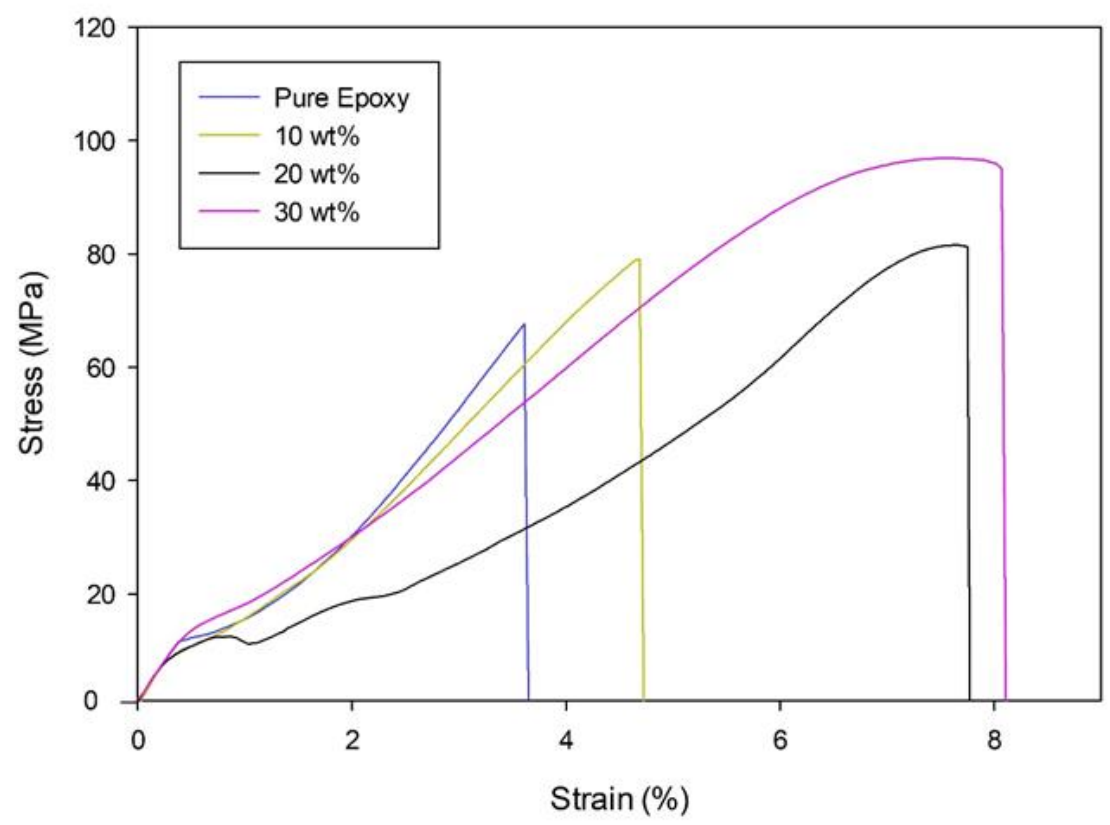

Fig. 6. Tensile stress vs. strain of silk fiber reinforced epoxy composites

The tensile strength exhibits a maximum value of $91.61 \mathrm{MPa}$ with $30 \mathrm{wt} . \%$ of fibre loading, which indicates that the tensile strength was improved by $30.73 \%$ compared to that of the pure epoxy (Figure 7). The enhanced interfacial bonding led to better load transfer between the silk fiber and the epoxy matrix, resulting in the high tensile strength of the composites [29-31]. Young modulus represents the stiffness of a material. The higher the modulus, the stiffer the material. Young 
modulus of pure epoxy was $3.14 \mathrm{GPa}$, and it was slightly decreased at $10 \mathrm{wt} . \%$ and then, slightly increased up to $30 \mathrm{wt} . \%$ of fibre loading $(3.7 \mathrm{GPa})$, indicating a successful reinforcing effect of about $17.8 \%$. Figure 8 shows that the elongation at break of silk fibre reinforced epoxy composites increased as silk fibre loading increased. The highest elongation at break was $8.20 \%$ at $30 \mathrm{wt} . \%$ of fibre, implying that the ductility of the epoxy matrix was significantly improved. The enhancement of elongation at break is due to the incorporation of silk fiber, which is ductile.

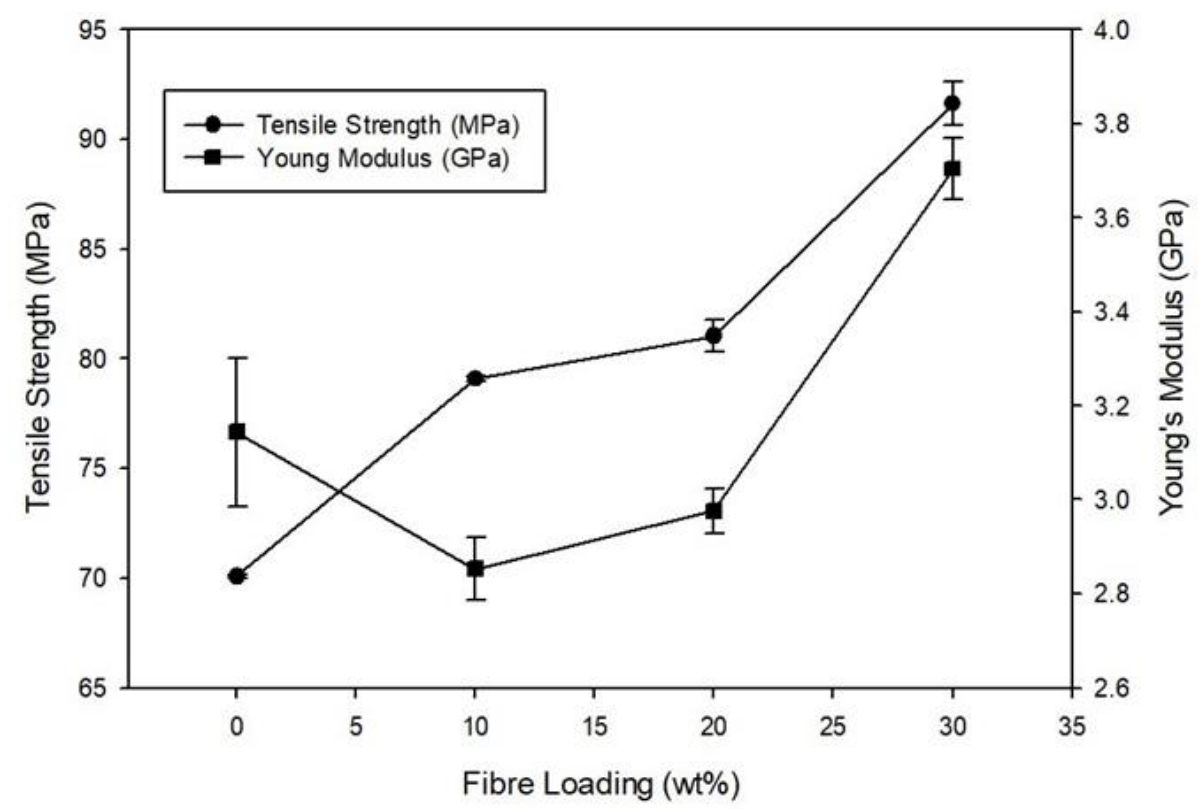

Fig. 7. Effect of the silk fiber content on the tensile strength and Young's modulus of silk fiber reinforced epoxy composites

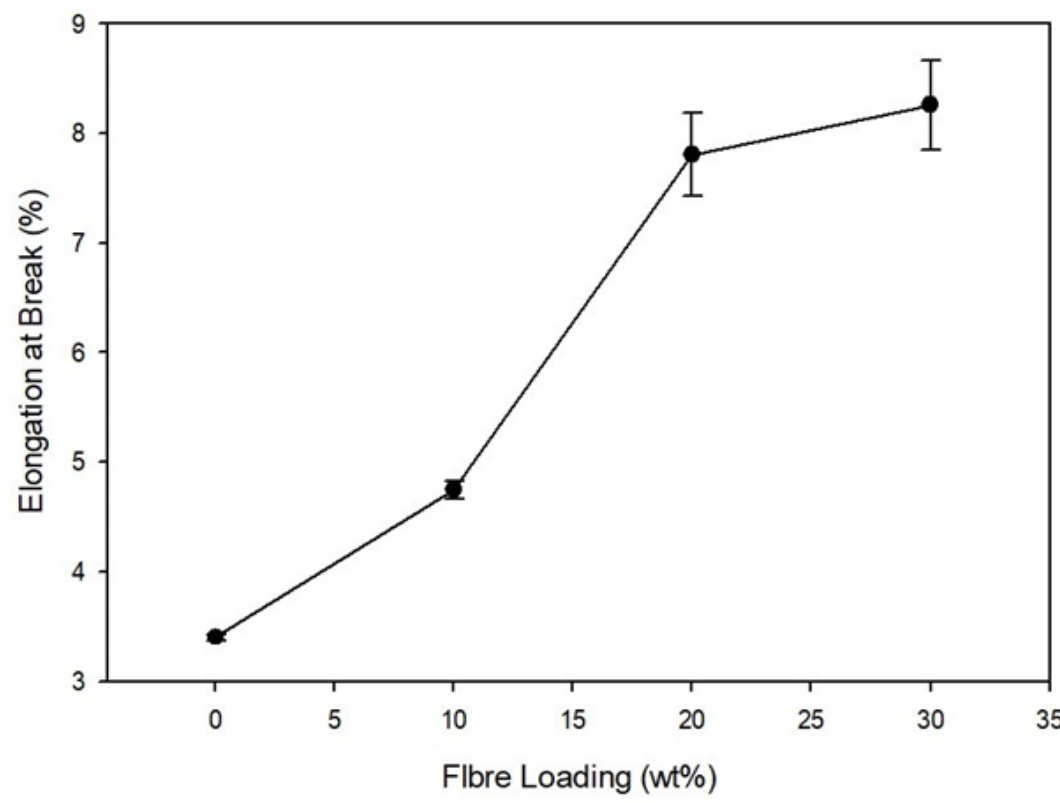

Fig. 8. Effect of the silk fiber content on the elongation at break of silk fiber reinforced epoxy composites

Figure 9 shows the typical flexural stress- strain graph effect of the composites. The flexural stress was obtained by determining the highest value of flexural strength as shown in Figure 10, while the flexural modulus was obtained by the initial slope or the gradient of the stress vs strain graph. The 
flexural strength and flexural modulus of the pure epoxy was 121.18 MPa and 4.02 GPa, respectively. The flexural strength was slightly decreased to $104.42 \mathrm{MPa}$ when the fibre loading was increased to $10 \mathrm{wt} . \%$, and significantly increased up to $30 \mathrm{wt} . \%$ of fibre loading.

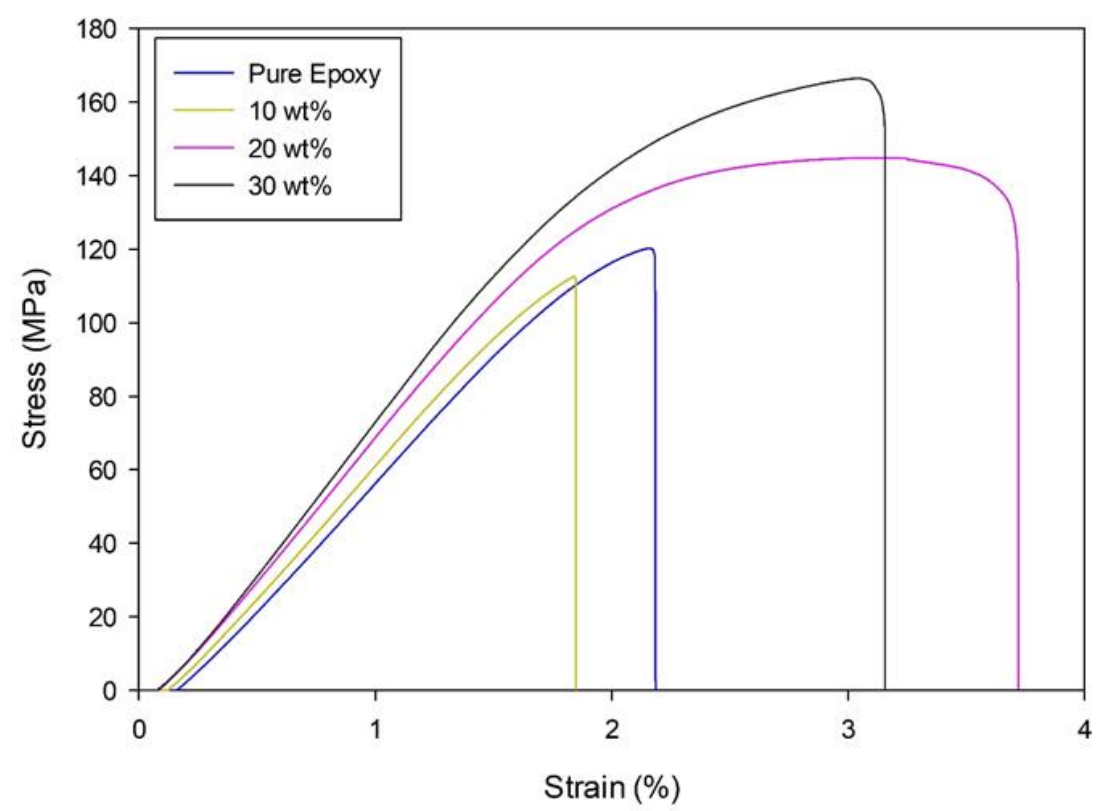

Fig. 9. Tensile stress vs. strain of silk fiber reinforced epoxy composites

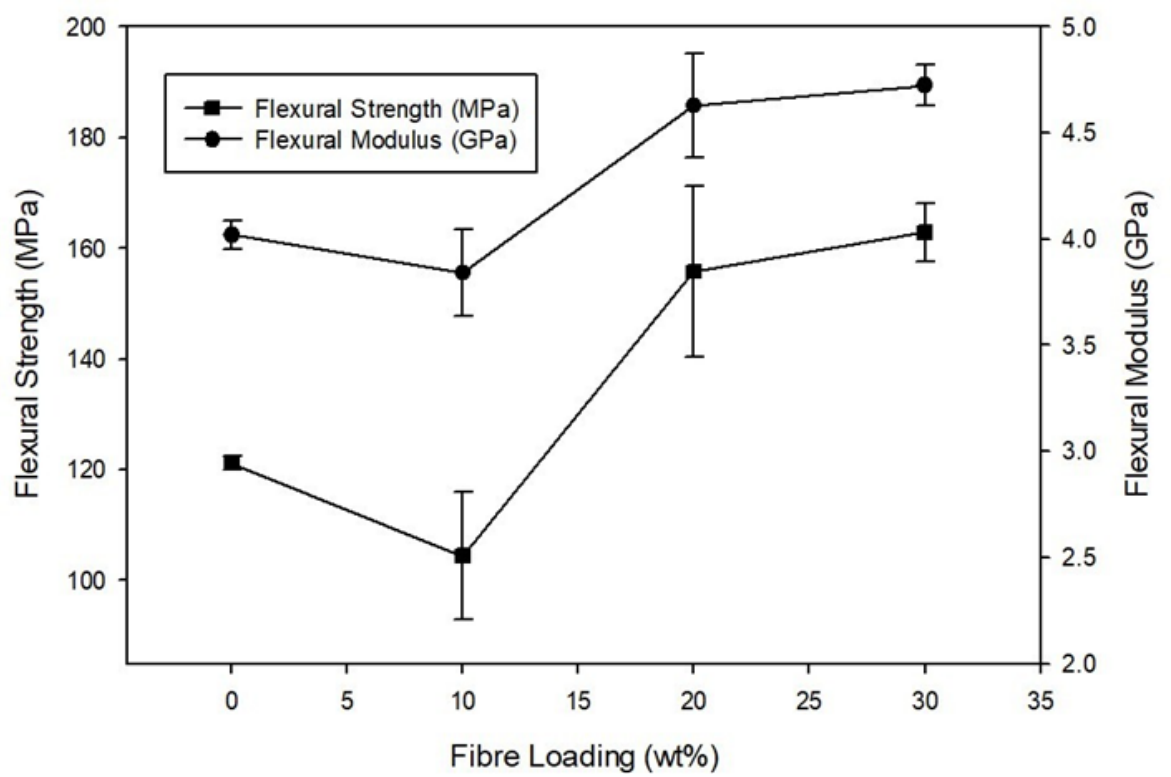

Fig. 10. Effect of the silk fiber loading on the flexural strength and flexural modulus of silk fiber reinforced epoxy composites

The flexural modulus of the composites shows the same pattern with the flexural strength of the composites. This is maybe due to the incorporation of the reinforcing agent, which is silk fibre that can withstand bending with breaking better than the plant fibres, and thus improve the flexural properties of the composites [32]. According to Abdul Khalil et al., [34], the flexural properties will slightly drop to a certain amount of fibre, before showing any enhancement on flexural properties. The decrement at $10 \mathrm{wt} . \%$ of fibre loading is due to the lack of silk fibre that was incorporated to the epoxy composites [33-34]. 
Figure 11 shows the effect of increasing fibre loading on the notched lzod impact strengths of the silk fibre reinforced epoxy composites. The impact strength of pure epoxy was $4.51 \mathrm{~kJ} / \mathrm{m} 2$. The impact strength of silk fibre reinforced epoxy composite increased with the increase in silk fibre loading. The maximum impact strength of silk fibre reinforced epoxy composites was $17.12 \mathrm{KJ} / \mathrm{m} 2$ at $30 \mathrm{wt} . \%$ of fibre loading. This represented approximately $191.66 \%$ increment in impact strength for $30 \mathrm{wt} . \%$ of fibre loading. The impact strength graph shows that the incorporation of silk fibres improved the impact strength properties due to more energy required to be used up to break the coupling bond between the interlaced fibre bundles. The reason that may contribute to the enhancement in composite toughness for composites is the difficulty to break strong and flexible fibroins in the silk fibre. The highly crystalline structure of fibroins gave strength and toughness to the silk fibre and therefore enhanced capability of silk fibre absorbing energy applied towards the composites and resisting the crack propagation at the notched specimen [35-36].

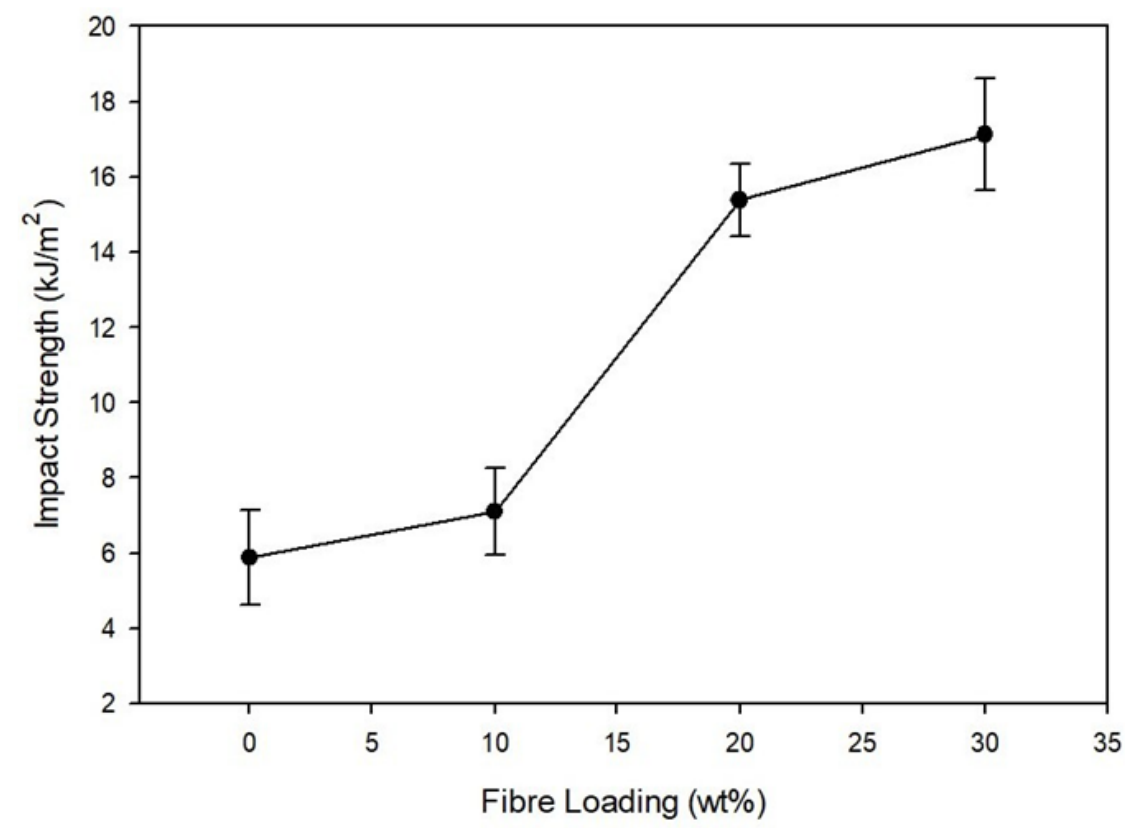

Fig. 11. Effect of the silk fiber loading on the impact strength of silk fiber reinforced epoxy composites

\subsection{Scanning Electron Micrography (SEM)}

Figure 12 shows the SEM images of the impact fracture surface morphology of pure epoxy resin and silk fibre reinforced epoxy composites at various fibre loading. The pure epoxy resin exhibits a smooth surface with wavelike pattern of deformation, indicating that it is a brittle material as shown in Figure 12(a). Since silk fibre possesses hydrophilic and hydrophobic parts, it is believed that it might have good interfacial bonding with hydrophobic matrix [36]. From the SEM images, some pull-out fibres and fibre tearing were observed due to the impact test. Figure 12(d) shows that the amount of pull-out fibre in the silk fibre reinforced epoxy composites at 30 wt.\% of fibre loading was considerably less than that of the silk fibre reinforced epoxy composites at lower fibre loading [24]. The image analysis also shows that there were more matrix cracking and spaces at the lower fibre loading due to the pull-out fibre phenomenon as shown in Figures 12(b) and (c). This indicates that the composite still has its brittle nature properties due to the lack of reinforcing agent which is silk fibre. At higher fibre loading, the image analysis of the sample shows less matrix cracking and spaces. This indicates that the composite at higher fibre loading (30 wt.\%) possesses better adhesion 
between fibre and matrix, which is consistent with the result obtained in the impact test. To improve the interfacial adhesion between silk fibre and matrix, an appropriate fibre surface modification such as silane treatment is required [37].

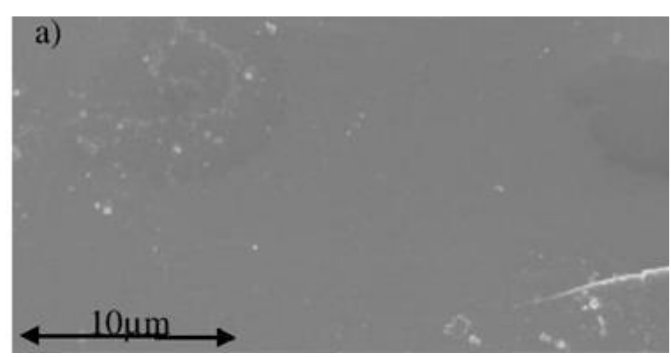

(a)

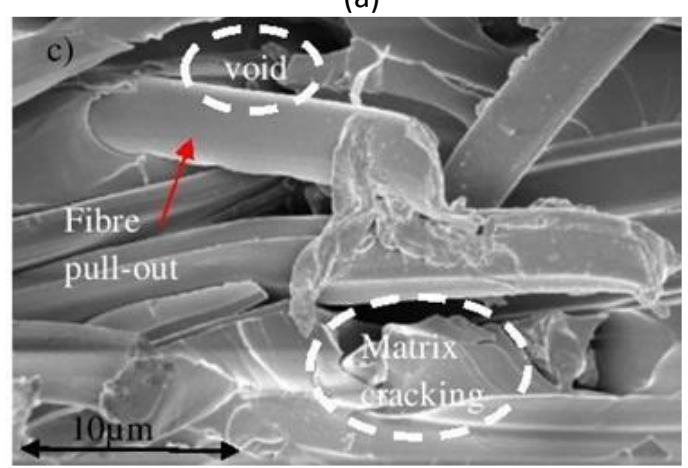

(c)

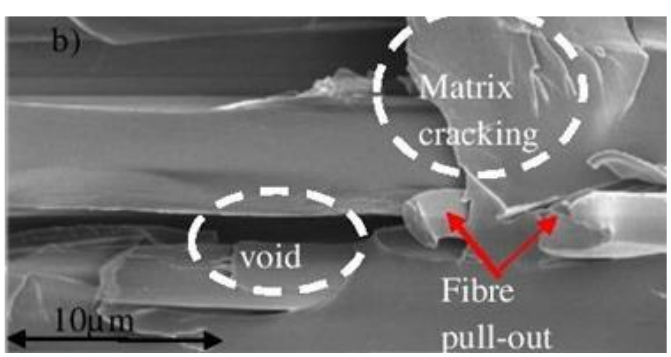

(b)

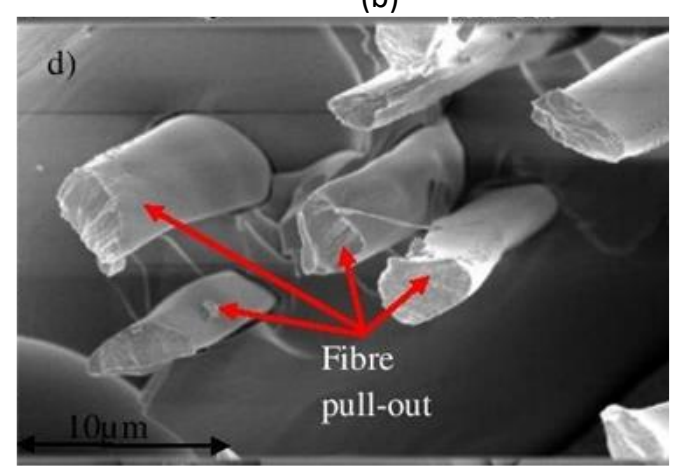

(d)

Fig. 12. Effect of the silk fiber loading on the impact strength of silk fiber reinforced epoxy composites

\subsection{Water Absorption Test}

The water absorption of silk fibre reinforced epoxy composites with up to $30 \mathrm{wt} . \%$ of fibre loading is shown in Figure 13. After approximately $552 \mathrm{hr}$, the water absorbed by the composites was stabilised.

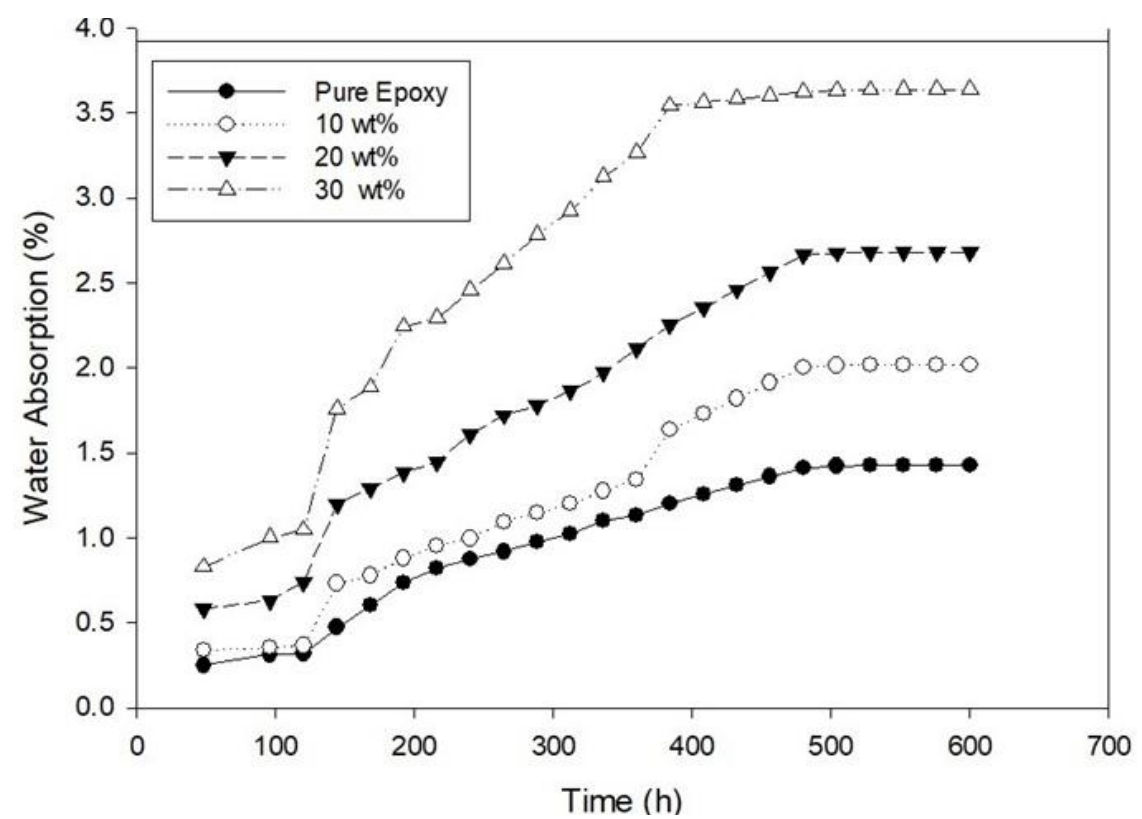

Fig. 13. Water absorption curve of silk fiber reinforced epoxy composite for different fiber loading 
It could be seen that the composites water absorption levels were less than $1.0 \%$ in the early stage of the test, the water absorption level of the composites was less than $1.0 \%$, and it increased correspondingly as the fibre loading was increased. In particular, the highest rate of water uptake was found within approximately $400 \mathrm{hr}$. Increased final water absorption percentage was also observed at approximately $552 \mathrm{hr}$ when the fibre volume loading was increased from 10 to $30 \mathrm{wt} . \%$. The water absorption level of pure epoxy was the lowest because the hydrophobic nature of the matrix has caused low diffusion of water through the polymer matrix [38]. Meanwhile, the silk fibre reinforced epoxy composites with $30 \mathrm{wt}$.\% of fibre loading has the highest water absorption levels. This result was expected due to the higher loading of silk fibre in the composite. Due to the hydrophilic characteristic of silk fibre, increased fibre loading will increase the number of peptide bonds (polar hydroxyl side-groups) in silk fibre. Thus, it increases the capability of silk fibre to hold the water molecule via hydrogen bonding [37].

\section{Conclusions}

In this study, it can be concluded that the silk fibre reinforced epoxy composites with $30 \mathrm{wt} . \%$ of fibre loading had the highest tensile strength, Young's modulus, and elongation at break compared to those of the pure epoxy, and other composites with 10 and 20 wt.\% of fibre loading. The flexural properties show that the composites with $30 \mathrm{wt} . \%$ of fibre loading possessed the highest flexural strength and modulus. Impact testing also shows that the silk fibre reinforced epoxy composites with 30 wt.\% fibre loading had the highest impact strength. For impact testing, SEM micrographs reveal that the pure epoxy had the smooth and fine morphology, while silk fibre reinforced epoxy composites with 30 wt.\% of fibre loading had less pull-out fibre, fewer spaces, less matrix cracking compared to other composites. This shows that the silk fibre reinforced epoxy composite with 30 wt.\% of fibre loading had better interfacial adhesion, which improved the impact strength of the composites. The incorporation of silk fibre into epoxy matrix also increased the water absorption properties because of the hydrophilic nature of silk fibre.

\section{Acknowledgement}

This research work is supported and funded by Universiti Teknologi Malaysia through research grant no. Q.J130000.2546.18H85.

\section{References}

[1] Paluvai, Nagarjuna Reddy, Smita Mohanty, and S. K. Nayak. "Synthesis and modifications of epoxy resins and their composites: a review." Polymer-Plastics Technology and Engineering 53, no. 16 (2014): 1723-1758. https://doi.org/10.1080/03602559.2014.919658

[2] Pham, H. L., B. T. Do, T. S. Pham, and D. G. Le. "Toughening of Bisphenol-A Diglycidyl Ether-based Epoxy by Modification with Hydroxyl-terminated Liquid Natural Rubber." ASEAN Journal on Science and Technology for Development 30, no. 1\&2 (2013): 22-28.

https://doi.org/10.29037/ajstd.346

[3] Rafique, Irum, Ayesha Kausar, and Bakhtiar Muhammad. "Epoxy resin composite reinforced with carbon fiber and inorganic filler: Overview on preparation and properties." Polymer-Plastics Technology and Engineering 55, no. 15 (2016): 1653-1672. https://doi.org/10.1080/03602559.2016.1163597

[4] Barcia, Fabio L., Thiago P. Amaral, and Bluma G. Soares. "Synthesis and properties of epoxy resin modified with epoxy-terminated liquid polybutadiene." Polymer 44, no. 19 (2003): 5811-5819. https://doi.org/10.1016/S0032-3861(03)00537-8

[5] Pickering, Kim L., MG Aruan Efendy, and Tan Minh Le. "A review of recent developments in natural fibre composites and their mechanical performance." Composites Part A: Applied Science and Manufacturing 83 (2016): 98-112. https://doi.org/10.1016/i.compositesa.2015.08.038 
[6] Bachtiar, D., S. M. Sapuan, and M. M. Hamdan. "The influence of alkaline surface fibre treatment on the impact properties of sugar palm fibre-reinforced epoxy composites." Polymer-Plastics Technology and Engineering 48, no. 4 (2009): 379-383. https://doi.org/10.1080/03602550902725373

[7] Faruk, Omar, Andrzej K. Bledzki, Hans-Peter Fink, and Mohini Sain. "Progress report on natural fiber reinforced composites." Macromolecular Materials and Engineering 299, no. 1 (2014): 9-26. https://doi.org/10.1002/mame.201300008

[8] Cristaldi, Giuseppe, Alberta Latteri, Giuseppe Recca, and Gianluca Cicala. "Composites based on natural fibre fabrics." Woven fabric engineering 17 (2010): 317-342.

[9] Faruk, Omar, Andrzej K. Bledzki, Hans-Peter Fink, and Mohini Sain. "Biocomposites reinforced with natural fibers: 2000-2010." Progress in polymer science 37, no. 11 (2012): 1552-1596. https://doi.org/10.1016/i.progpolymsci.2012.04.003

[10] La Mantia, F. P., and M. Morreale. "Green composites: a brief review. Compos A Appl Sci Manuf 42 (6): 579-588." (2011). https://doi.org/10.1016/i.compositesa.2011.01.017

[11] Zhao, Yong-Qing, Hoi-Yan Cheung, Kin-Tak Lau, Cai-Ling Xu, Dan-Dan Zhao, and Hu-Lin Li. "Silkworm silk/poly (lactic acid) biocomposites: Dynamic mechanical, thermal and biodegradable properties." Polymer degradation and stability 95, no. 10 (2010): 1978-1987. https://doi.org/10.1016/i.polymdegradstab.2010.07.015

[12] Yang, Kang, Robert O. Ritchie, Yizhuo Gu, Su Jun Wu, and Juan Guan. "High volume-fraction silk fabric reinforcements can improve the key mechanical properties of epoxy resin composites." Materials \& Design 108 (2016): 470-478.

https://doi.org/10.1016/i.matdes.2016.06.128

[13] Gerritsen, Vivienne Baillie. "The tiptoe of an airbus." Protein Spotlight (2013): 1-2.

[14] Hardy, John G., and Thomas R. Scheibel. "Composite materials based on silk proteins." Progress in Polymer Science 35, no. 9 (2010): 1093-1115.

https://doi.org/10.1016/i.progpolymsci.2010.04.005

[15] Scheibel, Thomas. "Spider silks: recombinant synthesis, assembly, spinning, and engineering of synthetic proteins." Microbial cell factories 3, no. 1 (2004): 14.

https://doi.org/10.1186/1475-2859-3-14

[16] Sheik, Sareen, and Gundibasappa Karikannar Nagaraja. "Development, Characterization and Properties of Silk Fibre and Grafted Silk Fibre Reinforced Polymer Composite Films." In Generation, Development and Modifications of Natural Fibers. IntechOpen, 2019. https://doi.org/10.5772/intechopen.85022

[17] Altman, Gregory H., Frank Diaz, Caroline Jakuba, Tara Calabro, Rebecca L. Horan, Jingsong Chen, Helen Lu, John Richmond, and David L. Kaplan. "Silk-based biomaterials." Biomaterials 24, no. 3 (2003): 401-416. https://doi.org/10.1016/S0142-9612(02)00353-8

[18] Hakimi, Osnat, David P. Knight, Fritz Vollrath, and Pankaj Vadgama. "Spider and mulberry silkworm silks as compatible biomaterials." Composites Part B: Engineering 38, no. 3 (2007): 324-337. https://doi.org/10.1016/i.compositesb.2006.06.012

[19] Humenik, Martin, Thomas Scheibel, and Andrew Smith. "Spider silk: understanding the structure-function relationship of a natural fiber." In Progress in molecular biology and translational science, vol. 103, pp. 131-185. Academic Press, 2011. https://doi.org/10.1016/B978-0-12-415906-8.00007-8

[20] Zhao, Liang, Hao Wang, Jie Luo, Cheng Cai, Guo L. Song, and Guo Y. Tang. "Fabrication of silk fibroin film with properties of thermal insulation and temperature monitoring Part B Polymer physics." (2016). https://doi.org/10.1002/polb.24087

[21] Gupta, Pratima, and Kush Kumar Nayak. "Characteristics of protein-based biopolymer and its application." Polymer Engineering \& Science 55, no. 3 (2015): 485-498. https://doi.org/10.1002/pen.23928

[22] Chen, Fujia, David Porter, and Fritz Vollrath. "Silk cocoon (Bombyx mori): multi-layer structure and mechanical properties." Acta Biomaterialia 8, no. 7 (2012): 2620-2627. https://doi.org/10.1016/i.actbio.2012.03.043

[23] Cheung, Hoi-Yan, Kin-Tak Lau, Xiao-Ming Tao, and David Hui. "A potential material for tissue engineering: Silkworm silk/PLA biocomposite." Composites Part B: Engineering 39, no. 6 (2008): 1026-1033. https://doi.org/10.1016/i.compositesb.2007.11.009 
[24] Li, Wei, Xiuying Qiao, Kang Sun, and Xiaodong Chen. "Mechanical and viscoelastic properties of novel silk fibroin fiber/poly ( $\varepsilon$-caprolactone) biocomposites." Journal of applied polymer science 110, no. 1 (2008): 134-139. https://doi.org/10.1002/app.28514

[25] Shubhra, Quazi TH, A. K. M. M. Alam, and M. D. H. Beg. "Mechanical and degradation characteristics of natural silk fiber reinforced gelatin composites." Materials letters 65, no. 2 (2011): 333-336. https://doi.org/10.1016/i.matlet.2010.09.059

[26] Ho, Mei-po, Kin-tak Lau, Hao Wang, and Debes Bhattacharyya. "Characteristics of a silk fibre reinforced biodegradable plastic." Composites Part B: Engineering 42, no. 2 (2011): 117-122. https://doi.org/10.1016/i.compositesb.2010.10.007

[27] Shah, Darshil U., David Porter, and Fritz Vollrath. "Opportunities for silk textiles in reinforced biocomposites: Studying through-thickness compaction behaviour." Composites Part A: Applied Science and Manufacturing 62 (2014): 1-10. https://doi.org/10.1016/j.compositesa.2014.03.008

[28] Yang, Kang, Sujun Wu, Juan Guan, Zhengzhong Shao, and Robert O. Ritchie. "Enhancing the mechanical toughness of epoxy-resin composites using natural silk reinforcements." Scientific reports 7, no. 1 (2017): 1-9. https://doi.org/10.1038/s41598-017-11919-1

[29] Kushwaha, Pradeep K., and Rakesh Kumar. "Effect of silanes on mechanical properties of bamboo fiber-epoxy composites." Journal of Reinforced Plastics and Composites 29, no. 5 (2010): 718-724. https://doi.org/10.1177/0731684408100691

[30] Bisanda, E. T. N., and Martin P. Ansell. "The effect of silane treatment on the mechanical and physical properties of sisal-epoxy composites." Composites Science and Technology 41, no. 2 (1991): 165-178. https://doi.org/10.1016/0266-3538(91)90026-L

[31] Prakash, VR Arun, and R. Viswanthan. "Fabrication and characterization of echinoidea spike particles and kenaf natural fibre-reinforced Azadirachta-Indica blended epoxy multi-hybrid bio composite." Composites Part A: Applied Science and Manufacturing 118 (2019): 317-326. https://doi.org/10.1016/i.compositesa.2019.01.008

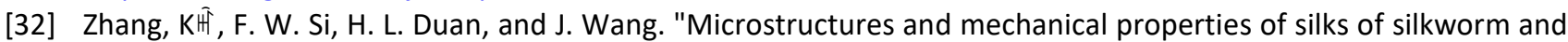
honeybee." Acta biomaterialia 6, no. 6 (2010): 2165-2171. https://doi.org/10.1016/j.actbio.2009.12.030

[33] Abdul Khalil, H. P. S., R. N. Kumar, S. M. Asri, N. A. Nik Fuaad, and M. N. Ahmad. "Hybrid thermoplastic pre-preg oil palm frond fibers (OPF) reinforced in polyester composites." Polymer-Plastics Technology and Engineering 46, no. 1 (2007): 43-50. https://doi.org/10.1080/03602550600948749

[34] Agarwal, G., A. Patnaik, and R. K. Sharma. "Mechanical and thermo-mechanical properties of bi-directional and short carbon fiber reinforced epoxy composites." Journal of Engineering Science and Technology 9, no. 5 (2014): 590-604.

[35] Mishra, Vivek, and Sandhyarani Biswas. "Physical and mechanical properties of bi-directional jute fiber epoxy composites." Procedia engineering 51 (2013): 561-566.

https://doi.org/10.1016/j.proeng.2013.01.079

[36] Pereira, Rui FP, Maria M. Silva, and Verónica de Zea Bermudez. "Bombyx mori silk fibers: An outstanding family of materials." Macromolecular Materials and Engineering 300, no. 12 (2015): 1171-1198. https://doi.org/10.1002/mame.201400276

[37] Kim, Byung Kuk, Oh Hyeong Kwon, Won Ho Park, and Donghwan Cho. "Thermal, mechanical, impact, and water absorption properties of novel silk fibroin fiber reinforced poly (butylene succinate) biocomposites." Macromolecular Research 24, no. 8 (2016): 734-740. https://doi.org/10.1007/s13233-016-4102-9

[38] Lu, Xun, Ming Qiu Zhang, Min Zhi Rong, and Gui Cheng Yang. "Environmental degradability of self-reinforced composites made from sisal." Composites science and technology 64, no. 9 (2004): 1301-1310. https://doi.org/10.1016/j.compscitech.2003.10.013 